\title{
Optical Spectroscopy Study of Transparent Non- Carious Human Dentin and Dentin-Enamel Junction
}

S.G. Demos, M. Balooch, G.W. Marshall, S.J. Marshall and R.R. Gallagher

This article was submitted to

Society of Photo-Optical Instrumentation Engineers Photonics West San Jose, $C A$

January 23-28, 2000

U.S. Department of Energy

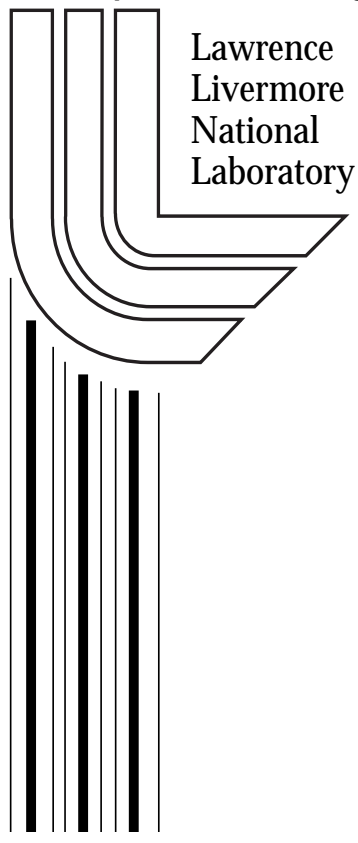

December 14, 1999 


\section{DISCLAIMER}

This document was prepared as an account of work sponsored by an agency of the United States Government. Neither the United States Government nor the University of California nor any of their employees, makes any warranty, express or implied, or assumes any legal liability or responsibility for the accuracy, completeness, or usefulness of any information, apparatus, product, or process disclosed, or represents that its use would not infringe privately owned rights. Reference herein to any specific commercial product, process, or service by trade name, trademark, manufacturer, or otherwise, does not necessarily constitute or imply its endorsement, recommendation, or favoring by the United States Government or the University of California. The views and opinions of authors expressed herein do not necessarily state or reflect those of the United States Government or the University of California, and shall not be used for advertising or product endorsement purposes.

This is a preprint of a paper intended for publication in a journal or proceedings. Since changes may be made before publication, this preprint is made available with the understanding that it will not be cited or reproduced without the permission of the author.

This report has been reproduced directly from the best available copy.

Available to DOE and DOE contractors from the

Office of Scientific and Technical Information

P.O. Box 62, Oak Ridge, TN 37831

Prices available from (423) 576-8401

http:/ / apollo.osti.gov/bridge/

Available to the public from the National Technical Information Service

U.S. Department of Commerce 5285 Port Royal Rd., Springfield, VA 22161 http://www.ntis.gov/

OR

Lawrence Livermore National Laboratory Technical Information Department's Digital Library http://www.llnl.gov/tid/Library.html 
UCRL-JC-136890

\title{
Optical Spectroscopy study of Transparent Non-Carious Human Dentin and Dentin-Enamel Junction
}

\author{
S. G. Demos, M. Balooch \\ Lawrence Livermore National Laboratory, PO Box 808, Livermore, CA 94580. \\ Tel.: (925) 423 3388, Fax: (925) 4232463 \\ G.W. Marshall, S.J. Marshall and R.R. Gallagher \\ University of California at San Francisco, Department of Restorative Dentistry \\ 707 Pamassus Ave., D2246, San Francisco, CA, 94143
}

\begin{abstract}
Improving our knowledge of the morphology, composition and properties of the dentin, enamel, and the dentin-enamel junction (DEJ) is vital for the development of improved restorative materials and clinical placement techniques. Most studies of dental tissues have used light microscopy for characterization. In our investigation, the spectroscopic properties of normal and non-carious transparent human root dentin, and the dentin-enamel junction were investigated using emission imaging microscopy, and micro-spectroscopy. Experimental results reveal new information on the structural and biochemical characteristics of these dental tissues.
\end{abstract}

Key words: Dentin, DEJ, Laser-induced fluorescence spectroscopy

\section{INTRODUCTION}

A tooth is primarily composed of four tissues: enamel, dentin, pulp and the dentin-enamel junction (DEJ). Enamel is the most calcified tissue in the body, forming a hard, brittle, thin shell covering the top of the tooth. It is composed of a calcium-deficient, carbonate-rich hydroxyapatite, which is arranged in parallel rods or prisms 4 to $5 \mu \mathrm{m}$ in diameter. The enamel prisms are composed of highly oriented and extremely long hydroxyapatite crystals. Enamel is composed of 85 volume percent mineral, 3 volume percent organic matter, and 12 volume percent fluid [1]. It functions to provide an abrasive resistant, hard, brittle shell to resist the stresses of mastication [2].

By contrast, dentin is a much tougher biomaterial. It is composed of oriented tubules, approximately 1-2 $\mu \mathrm{m}$ in diameter, which are embedded within a collagen matrix-apatite reinforced composite material called intertubular dentin. The tubules represent the formative tracks taken by the odontoblastic cells during their migration from the DEJ to the pulp chamber [3]. These tubules converge on the pulp chamber, therefore tubule density and orientation vary from location to location. Tubule number is lowest at the DEJ and highest at the predentin surface lining the pulp chamber, where the odontoblastic cell bodies lie in nearly a close packed array. Lower tubule densities are found in the root. Cellular odontoblastic processes are located within the dentinal tubules, and are surrounded by a 0.5-1 $\mu \mathrm{m}$ thick cuff of peritubular dentin [1]. Peritubular dentin is composed of randomly oriented carbonate rich, calcium deficient apatite crystals. Dentin functions to support enamel and distribute the occlusal stresses throughout the tooth [4]. The centrally located non-calcified pulp is composed of blood vessels, nerves, and supporting connective tissues. It acts to provide nourishment and moisture to the tooth. An important altered form of dentin is transparent dentin. Transparent dentin can take different forms, as a result of pathology or aging. It is not clear if these altered forms are the result of mineral accumulation, structural changes, or chemical changes.

The dentin-enamel junction or DEJ has been hypothesized to be an evolutionary conserved dental tissue that performs the function of joining two mechanically dissimilar calcified dental tissues. It plays critical roles as the initiation surface for ameloblastic and odontoblastic activity during tooth formation, and during maturation is probably critical to determining the biomechanical integrity of the 
tooth [2,5]. The structure of the DEJ has generally been described as scalloped with its convexities directed toward the dentin and concavities directed toward the enamel. This adaptation is thought to enhance bonding between these tissues. Little information concerning the thickness of this tissue exists. No description of the cells or materials, which comprise this tissue, have been found. It is believed that the DEJ is a less calcified tissue than either dentin or enamel, and probably contains a higher organic component. To date, it is not known for certain if this tissue exists. The DEJ has been hypothesized as being a microstructurally distinct and mechanically tougher portion of the tooth that is essential to terminating enamel cracks, and thereby preventing them propagating into the dentin and causing catastrophic fracture of the tooth [2].

Altered forms of dentin appear commonly, and may or may not be associated with a pathologic process. Transparent dentin is an important and relatively common modification of normal dentin. The dentinenamel junction is a structure that is believed to be responsible for preventing catastrophic tooth fracture. The DEJ functions to join hard, brittle enamel with tough dentin in such a manner as to optimize the mechanical performance of both tissues. It is not known if the DEJ exists, what its thickness is, or what type of tissue it is composed of. The microscopic nature of the DEJ, together with its intimate association with dentin and enamel has made it difficult to study its properties and structure. Therefore, it was the objective of this work was to study non-carious transparent human root dentin, and the dentin-enamel junction using optical spectroscopic tools to characterize these materials.

\section{EXPERIMENTAL SET-UP}

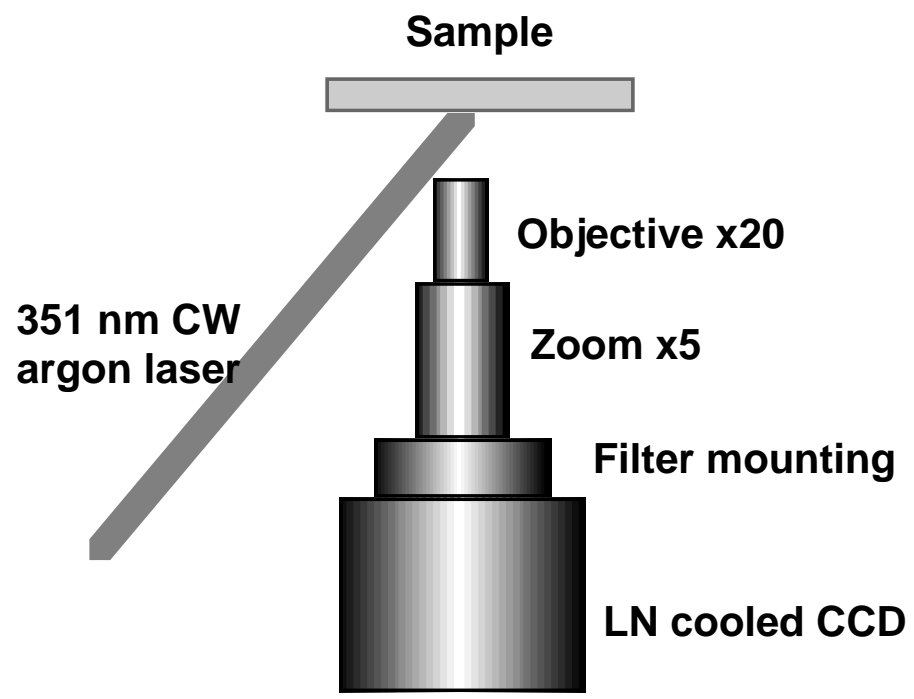

Figure 1. Schematic diagram of the microscopic fluorescence imaging. experimental setup

The experimental arrangement is shown in Fig. 1. The 351-nm output beam of an argon laser was used as the excitation source for the acquisition of microscopic fluorescence images. The incidence angle on the surface of the sample is approximately 45 degrees. The illuminated area of the sample is imaged using a microscope system that is positioned perpendicular to the surface of the sample. This imaging system is composed of a X20 magnification, 20-mm working distance microscope objective followed by a X5 magnification zoom lens. The images were captured using a liquid nitrogen cooled CCD detector. The desired spectra region of the emitted light by the sample is selected using the appropriate optical filters positioned on the filter mounting assembly located between the CCD and the zoom lens

The experimental effort included micro-spectroscopy tools to obtain spectral information with spatial resolution of a few-microns. The differences in the emission profiles were exploited by performing interimage operations to obtain high-resolution images highlighting the spectral differences of structures within the imaged area.

Recently extracted normal and altered human teeth were sterilized by gamma radiation prior to sectioning. ${ }^{6}$ Sample preparation consisted of sectioning the teeth into 1-millimeter thick slabs, and polishing them to $0.05 \mu \mathrm{m}$ with alumina slurry paste. The samples were then air dried for 24 hours. 


\section{RESULTS}

The emission spectra from normal and transparent dentin near the pulp as a result of Argon-ion laser excitation at $351 \mathrm{~nm}$ are shown in Figure 2a. The major peaks for both normal and transparent zones are near 420, 450 and $500 \mathrm{~nm}$. In normal dentin, the highest peak was found to be around $500 \mathrm{~nm}$. In transparent dentin the highest peak is near $450 \mathrm{~nm}$. In addition, the normal dentin exhibits higher emission in the infrared region (greater than $700 \mathrm{~nm}$ ) than does transparent dentin. These spectral differences were utilized to obtain microscopic fluorescence images of the sample. Figure $2 b$ shows an emission image obtained using a $700 \mathrm{~nm}$ long-pass filter to select the NIR emission for imaging. This image covers an area of $1 \mathrm{~mm}^{2}$, and includes both normal and transparent zones. Consistent with the spectra shown in Figure 1a, the normal zone exhibits higher emission intensity.

Higher magnification images of the locations where normal, transitional and transparent dentin exist are shown in Figures 3a, 3b, and 3c, respectively. Each image was adjusted to produce maximal contrast. Figure 3a reveals
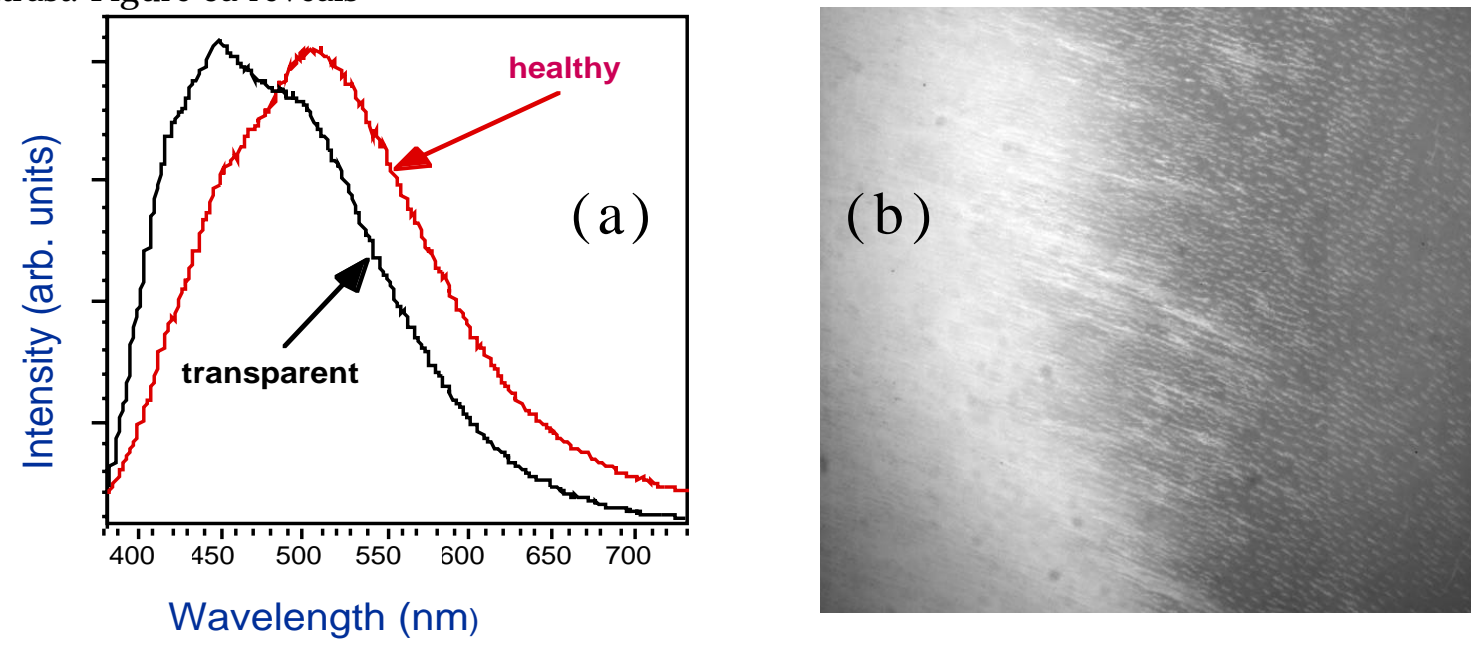

Figure 2: a) Emission spectra of normal and transparent dentin under $351 \mathrm{~nm}$ excitation, b) emission image of a $1 \mathrm{~mm}^{2}$ section including both normal and transparent zones obtained using a $700 \mathrm{~nm}$ long-pass filter.

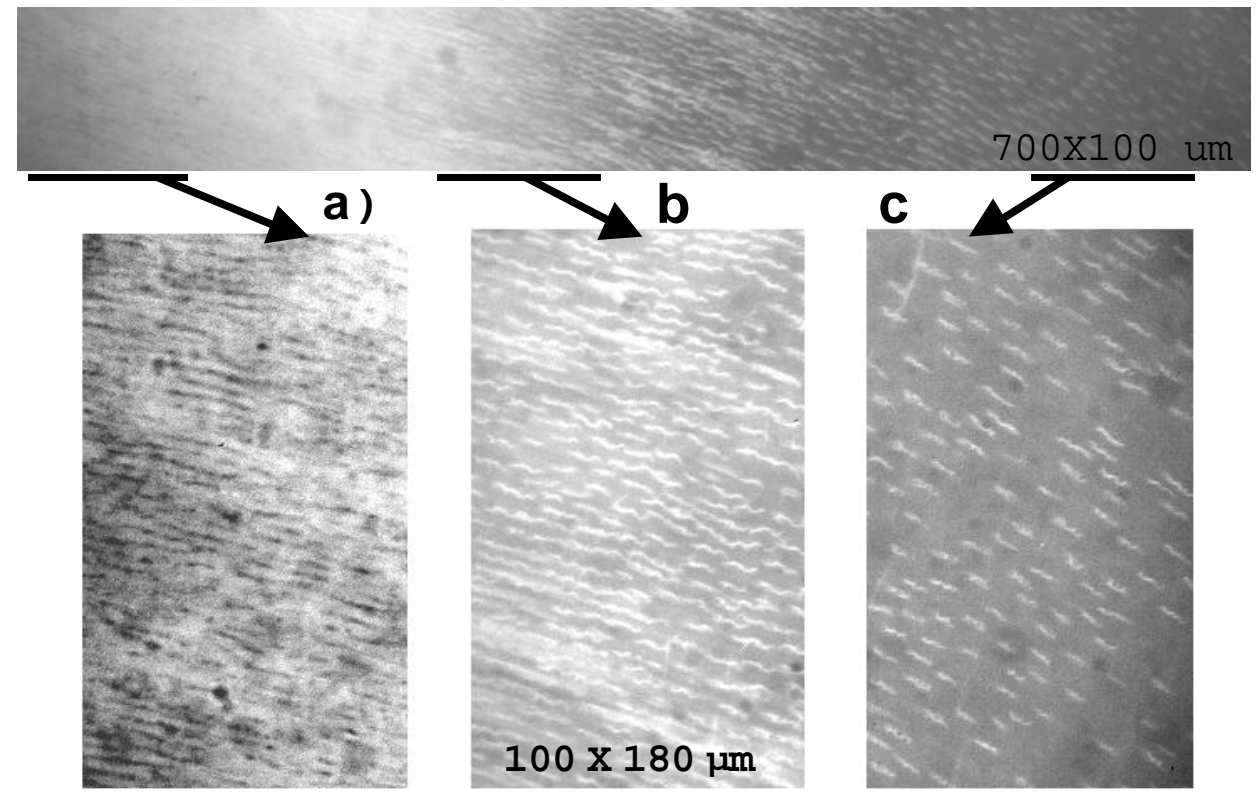


Figure 3: Microscopic fluorescence images from normal dentin (a), transitional dentin (b) and transparent dentin. Each image was individually adjusted to provide maximal contrast.

tubules that are less luminescent than the intertubular dentin, suggesting they are empty. In contrast, Figure 3c shows transparent dentin that has more emissive tubules with respect to intertubular dentin, suggesting that the tubules are filled with deposits. In Figure 3b, a transient zone of about 250 to $300 \mu \mathrm{m}$ is identified where the tubules are filled with deposits, but the intertubular dentin emission properties remain roughly the same as in the healthy dentin. The above experiments were complemented with other experiments where fluorescence images were obtained using different parts of the emission spectrum of dentin followed by inter-image operations to gain information regarding the spectral characteristics of the various constituents of human dentin.

Additional experiments were performed in the area of the dentin-enamel junction. Figure 4 shows an emission image of a $210 \mu \mathrm{m} \times 190 \mu \mathrm{m}$ section at the DEJ. In this image, enamel is located in the upper portion, dentin in the lower portion. The dentin-enamel junction appears as thin strip across the middle of the image. The dentinal tubules appear to be less luminous than the intertubular dentin strips, which are $2-\mu \mathrm{m}$ in diameter and $\approx 50 \mu \mathrm{m}$ long as a result of the plane of the section. The tubules actually extend from near the DEJ to the pulp chamber. We found that in our samples, the thickness of DEJ is approximately $10 \mu \mathrm{m}$.

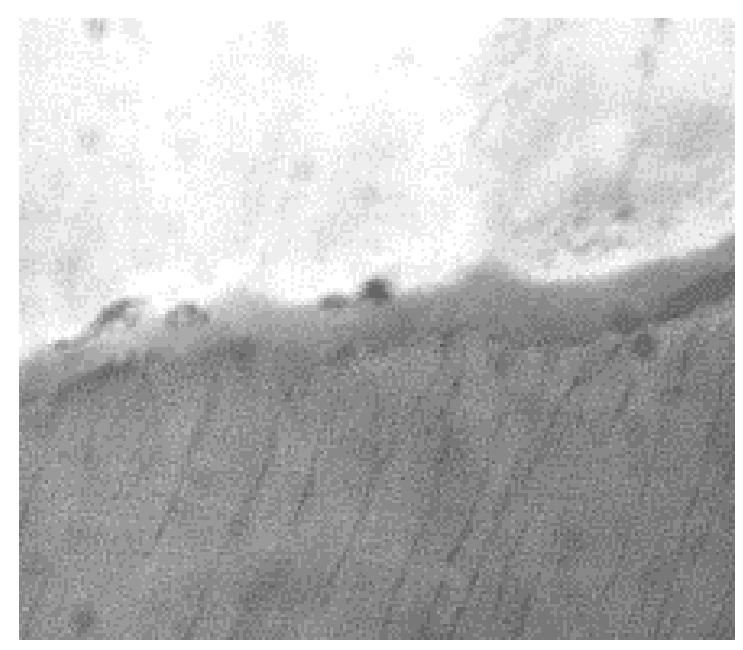

Figure 4: Microscopic fluorescence image of a $210 \mu \mathrm{m} \times 190 \mu \mathrm{m}$ section in the vicinity of the dentin-enamel junction. Enamel is located at the top, and dentin at the bottom of the image

\section{DISCUSSION}

Experimental results (see Fig. 3) image indicate a transition region of 250-300 $\mu \mathrm{m}$ that lies between the normal and transparent areas in which the tubules appear to be more emissive than the adjacent intertubular dentin. The intertubular dentin in this transition region had emission characteristics similar to those seen in the normal dentin. These results suggest that in the transition zone, the tubules are filled while the intertubular dentin is apparently not altered from that of normal dentin. Even though the luminescence intensity changes appreciably from normal to transparent dentin, it does not necessarily indicate changes in chemical composition. It has been suggested that changes in mineral concentration can affect fluorescence behavior by quenching or de-quenching as yet unidentified chromophores. For example, the change in intensity could be due to the increased mineral concentration that has been observed in these zones.

This method proved to be extremely useful and revealed significant differences between the transparent and normal dentin as well as showing a transition zone between these regions. It was also proved succesfull in imaging DEJ, as shown in fig. 4 . We found that in our samples, the thickness of DEJ is approximately $10 \mu \mathrm{m}$ and that the spectroscopic signature of DEJ is different to that of dentin and 
enamel. Most important, we are able to clearly identify the DEJ as being a distinctly separate structure from either dentin or enamel

\section{CONCLUSION}

Laser-induced fluorescence spectroscopy can be used to characterize enamel, normal dentin, transparent dentin, and the DEJ. The DEJ was found to be a spectroscopically distinct material that exhibited a sharp and clearly defined border. The DEJ was found to be roughly 10um thick.

\section{ACKNOWLEDGMENTS}

This work was performed at Lawrence Livermore National Laboratory under the auspices of the U.S. Department of Energy under Contract W-7405-Eng-48 through the Institute for Laser Science and Applications,

\section{REFERENCES}

1 Ten Cate AR. Oral Histology: development, structure and function. $4^{\text {th }}$ ed., St. Louis, MO: Mosby. 1994.

2 Lin CP, Douglas. Failure mechanisms at the human dentin-resin interface: a fracture mechanics approach. J Biomech 27(8):1037-1047, 1994.

3 Linde A. Dentin and dentinogenesis, Volume I. $1^{\text {st }}$ ed., Boca Raton, FL:CRC Press Inc., 1984.

4 Marshall GW. Dentin: Microstructure and characterization. Quintessence Int. 24:606-617, 1993.

5 Lin CP, Douglas. Structure-property relations and crack resistance at the bovine dentin-enamel junction. J Dent Res 73(5):1072-1078, 1994.

6 White JM, Goodis HE, Marshall SJ, Marshall GW. Sterilization of teeth by gamma radiation. J Dent Res 73:1560-1567, 1984. 